\title{
Polymorphisms in the Sortilin-Related Receptor 1 Gene Are Associated with Cognitive Impairment in Filipinos
}

\author{
Cristine R. Casingal, ${ }^{1,2}$ Maria Luisa G. Daroy, ${ }^{1,2}$ Cynthia A. Mapua, \\ Dianne Jane A. Florendo, ${ }^{1,3}$ Filipinas F. Natividad, ${ }^{1,2}$ and Jacqueline C. Dominguez ${ }^{3}$ \\ ${ }^{1}$ Research and Biotechnology, St. Luke's Medical Center, 279 E Rodriguez Sr. Boulevard, 1112 Quezon City, Philippines \\ ${ }^{2}$ St. Luke's College of Medicine William H. Quasha Memorial, E Rodriquez Sr. Boulevard, 1112 Quezon City, Philippines \\ ${ }^{3}$ Memory Center, Institute for Neuroscience, St. Luke's Medical Center, 279 E Rodriquez Sr. Boulevard, 1112 Quezon City, Philippines \\ Correspondence should be addressed to Cristine R. Casingal; tincasingal@gmail.com
}

Received 6 August 2014; Revised 23 October 2014; Accepted 6 November 2014; Published 27 November 2014

Academic Editor: Raymond Chuen-Chung Chang

Copyright (C) 2014 Cristine R. Casingal et al. This is an open access article distributed under the Creative Commons Attribution License, which permits unrestricted use, distribution, and reproduction in any medium, provided the original work is properly cited.

Background/Aims. Sortilin-related receptor 1 (SORL1) is involved in the neuronal transport processes and plays a role in the formation of amyloid plaques. This study investigated the association of 6 SORL1 single nucleotide polymorphisms (SNPs 8, 9, $10,13,19$, and 23) with cognitive impairment (CI) in Filipinos. Methods. DNA samples from 484 subjects (100 Alzheimer's Disease (AD) cases, 109 mild cognitive impairment (MCI) cases, 18 other types of CI, and 257 no dementia controls (NDC)) were genotyped using TaqMan SNP Genotyping Assays. Data Analysis. Our study showed strong linkage disequilibrium in the SNPs 8, 9, and 10 block. Our results showed that CI was significantly associated with SNPs 13 and 23. None of the SORL1 SNPs studied was associated with AD while SNPs 8, 9, 10, and 23 were associated with MCI. Conclusion. The findings had provided evidence that SORL1 may predispose individuals to CI. Further studies are needed to clarify the role of SORL1 in Filipinos with AD.

\section{Introduction}

Sortilin-related receptor 1 (SORL1) is genetically linked to Alzheimer's disease (AD) [1-7]. Recent evidence indicates that it acts as a regulatory gatekeeper for determining the ultimate destination of amyloid precursor protein (APP) [8]. APP processing generates the $\beta$-amyloid $(\mathrm{A} \beta)$ peptides, which are deposited as the amyloid plaques in brains of individuals with $\mathrm{AD}[9]$.

$A D$ was associated with the " $C$," " $G$," and " $C$ " alleles at single nucleotide polymorphisms (SNP) 8 , 9 , and 10 , in the $5^{\prime}$-end of SORL1, respectively and the "G" and "T" alleles at SNPs 19 and 23 in the $3^{\prime}$-end of SORL1, respectively [2]. Using frozen brain tissue from autopsy-confirmed AD cases, Lee et al. reported that some AD patients displayed low level of SORL1 [1]. These data suggest that inherited or acquired changes in SORL1 expression or function are mechanistically involved in causing $\mathrm{AD}$.

Mild cognitive impairment (MCI) refers to individuals who exhibit cognitive deficit but not dementia [10]. It has an incidence rate of 9.9/1000 person-years and an annual conversion rate of $10 \%$ to $12 \%$ to $\mathrm{AD}$, in contrast to a conversion rate of $1 \%$ to $2 \%$ in the normal elderly population [11]. Sager et al. reported that MCI subjects with low SORL1 expression levels were significantly more cognitively impaired than subjects with high levels of expressed SORL1 [10].

Currently, there has been no published data on the genetic variation of SORL1 in the Filipino population. In this study, we sought to investigate the role of SORL1 (SNPs 8, 9, 10, 13, 19, and 23) in Filipinos with cognitive impairment (CI), $\mathrm{MCI}$, and $\mathrm{AD}$ as well as its association with sex, age, and its

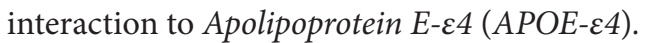

\section{Methodology}

2.1. Study Population. The Institutional Ethics Review Committee of the St. Luke's Medical Center approved the study protocol, and subjects were selected based on inclusion and exclusion criteria. Informed, written consent was obtained 

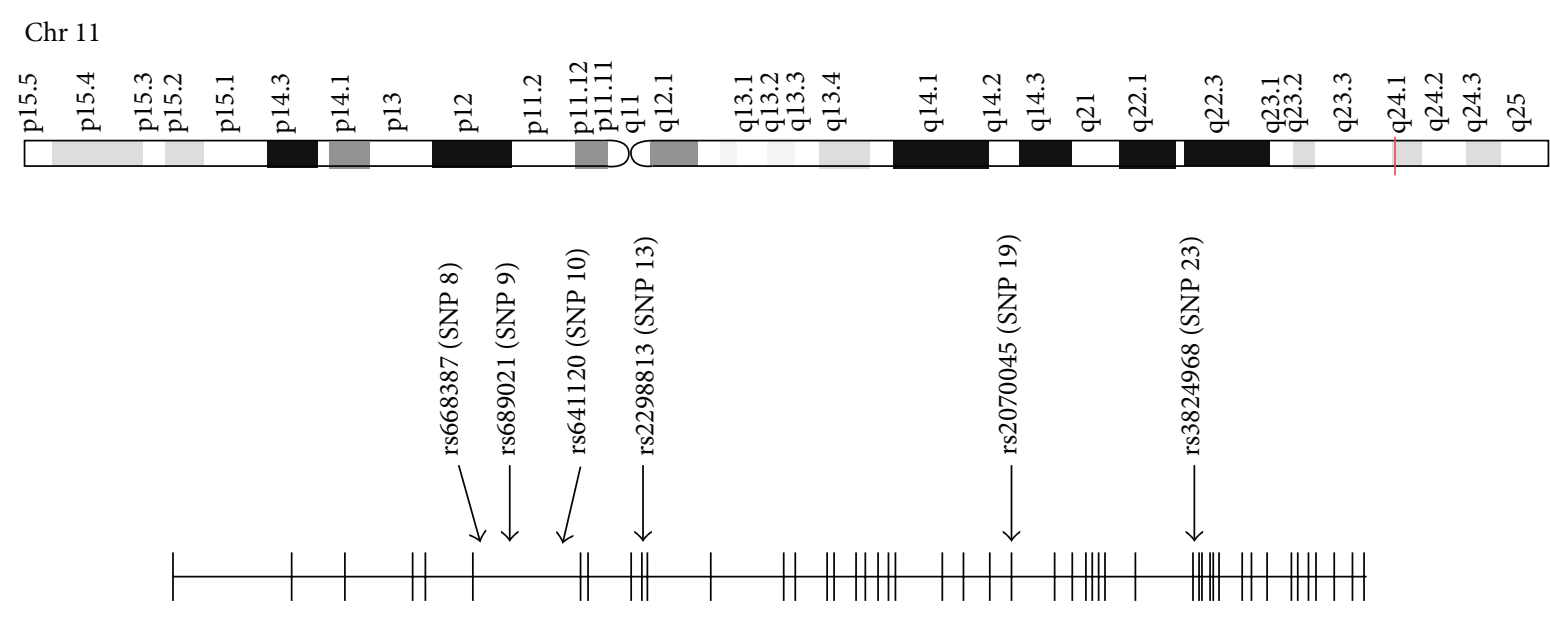

FIgURE 1: Chromosome location of SORL1 and the 6 SNPs.

from each subject or from reliable collateral informants who are familiar with the subject's cognitive state.

The group who evaluated the subjects consisted of a neurologist, psychologists, and a nurse. Every datagathering session began with briefing to include an intake interview for the demographic data and medical history using the Philippine Neurological Association (PNA) 10item Questionnaire for Common Neurological Diseases. Clinical dementia rating (CDR), assessment of the presence or absence of $\mathrm{AD}$ based on the National Institute of Neurological and Communicative Disorders and Stroke and the Alzheimer's Disease and Related Disorders Association (NINCDS-ADRDA) Alzheimer's criteria, Montreal Cognitive Assessment (MOCA), Mini-Mental State Exam (MMSEP), Disability Assessment for Dementia (DAD), Neuropsychiatric Inventory (NPI), and Geriatric Depression Scale (GDS) were individually administered to all the subjects.

2.2. SORL1 Genotyping. Five milliliters of whole blood in BD Vacutainer tubes with EDTA was drawn from each subject. DNA was extracted from the buffy coat using Qiagen QIAamp DNA extraction kit. Polymorphisms (numbering relative to AP000977.4), rs668387 (51432C>T), rs689021 $(54631 G>A), r s 641120(64476 \mathrm{G}>A), r s 2298813(77195 \mathrm{G}>\mathrm{A})$, rs2070045 (131601T>G), and rs3824968 $(159433 \mathrm{~T}>\mathrm{A})$ in the SORL1 gene, numbered as SNPs 8, 9, 10, 13, 19, and 23, respectively, were selected for testing (Figure 1). SNPs 8, 9, and 10 are located in the intron 6 of the gene while SNPs 13,19 , and 23 are located in exons 11,25 , and 34 , respectively. Genotyping was performed using TaqMan SNP Genotyping Assays (Applied Biosystems).

2.3. Data Analysis. For each SNP, goodness-of-fit to HardyWeinberg equilibrium (HWE) was assessed using the ChiSquare test $\left(\chi^{2}\right)$. Haploview ver. 4.2 software developed by the Broad Institute was used to estimate the degree of linkage disequilibrium (LD), to detect single marker association, and to determine presence of haplotype blocks [12]. The default settings were used in these analyses, which create $95 \%$ confidence bounds on $\mathrm{D}^{\prime}$ to delineate SNP pairs in strong LD.
SPSS ver. 16.0 software was used for the association analysis. Differences between the genotype and allele frequencies between the CI cases and no dementia controls (NDC) in Filipinos were determined by $\chi^{2}$ test. Univariate logistic regression was performed to determine the association of the SNPs with the CI cases. The association of the SORL1 SNPS with the CI cases was indicated in odds ratio (OR) with the corresponding 95\% confidence intervals. Stratified analyses were performed to determine if associations differed between sex, age, and Apolipoprotein E- $\varepsilon 4(A P O E-\varepsilon 4)$ groups. All tests were two-tailed and considered significant at $P<0.05$.

\section{Results}

3.1. Study Subjects. A total of 484 subjects including 227 (46.9\%) CI cases (100 with AD, 109 with MCI, and 18 with other types CI) and 257 (53.1\%) NDC were included in this study. There were 335 (69.2\%) females and 149 (30.8\%) males. The mean age was $70.5 \pm 7.9$ years old (y/o), $253(52.3 \%)$ were $\leq 70 \mathrm{y} / \mathrm{o}, 218(45.0 \%)$ were $<70 \mathrm{y} / \mathrm{o}$, and $13(2.7 \%)$ had no recorded age. APOE genotypes showed 391 (80.8\%) were $A P O E-\varepsilon 4$ noncarriers and 93 (19.2\%) were $A P O E-\varepsilon 4$ carriers.

3.2. SORL1 Genotypes. The allele and genotype frequencies of the SORL1 SNPs (Table 1) observed in this study population were in HWE, except for SNP $13\left(\chi^{2}=7.2127\right)$ which showed a significantly higher frequency for the G allele. When the $\chi^{2}$ of SNP 13 was computed for the NDC only, the result was in $\operatorname{HWE}\left(\chi^{2}=0.4084\right)$.

The alleles C, G, G, G, G, and A alleles of SNPs 8, 9, 10, 13,19 , and 23 , respectively, were detected as the risk alleles for the cognitively impaired population (Table 2). Haplotype block 1 showed a strong LD in SNPs 8, 9, and 10 (Figure 2). This block formed a three-locus haplotype, C-G-G, and T-AA. However, none of the haplotypes were associated with $\mathrm{CI}$, $\mathrm{MCI}$, and AD (data not shown).

3.3. Genetic Association Analysis. Individual SNPs were analyzed in the CI, MCI, and AD cases (Table 3). SNP 13 ( $P$ value 
TABLE 1: Goodness-of-fit to HWE for the elderly Filipinos studied.

\begin{tabular}{|c|c|c|c|c|c|c|c|c|c|c|c|c|c|}
\hline SNP\# & & Observe & & Total & $p$ obs & $q$ obs & $p^{2 \exp }$ & $2 p q^{\exp }$ & $q^{2 \exp }$ & $P \exp$ & $2 P Q \exp$ & $Q \exp$ & $x^{2}$ \\
\hline \multirow{2}{*}{8} & $\mathrm{CC}$ & TC & $\mathrm{TT}$ & & & & & & & & & & \\
\hline & 56 & 204 & 224 & 484 & 0.3265 & 0.6735 & 0.1066 & 0.4398 & 0.4537 & 52 & 213 & 219 & 0.8355 \\
\hline \multirow{2}{*}{9} & AA & GA & GG & & & & & & & & & & \\
\hline & 224 & 203 & 57 & 484 & 0.6725 & 0.3275 & 0.4523 & 0.4405 & 0.1072 & 219 & 213 & 52 & 1.1056 \\
\hline \multirow{2}{*}{10} & AA & GA & GG & & & & & & & & & & \\
\hline & 224 & 203 & 57 & 484 & 0.6725 & 0.3275 & 0.4523 & 0.4405 & 0.1072 & 219 & 213 & 52 & 1.1056 \\
\hline \multirow{2}{*}{13} & AA & GA & GG & & & & & & & & & & \\
\hline & 7 & 60 & 417 & 484 & 0.0764 & 0.9236 & 0.0058 & 0.1412 & 0.8530 & 3 & 68 & 413 & $7.2127^{*}$ \\
\hline \multirow{2}{*}{19} & $\mathrm{TT}$ & TG & GG & & & & & & & & & & \\
\hline & 75 & 218 & 191 & 484 & 0.3802 & 0.6198 & 0.1445 & 0.4713 & 0.3842 & 70 & 228 & 186 & 0.9488 \\
\hline \multirow{2}{*}{23} & TT & TA & AA & & & & & & & & & & \\
\hline & 89 & 227 & 168 & 484 & 0.4184 & 0.5816 & 0.1750 & 0.4867 & 0.3383 & 85 & 235 & 164 & 0.6381 \\
\hline
\end{tabular}

Legend:

$\chi^{2}$ tabulated $(\mathrm{dF}=1, P=0.05): 3.841$.

$p$ obs: observed frequency of homozygous Allele 1.

$q$ obs: observed frequency of homozygous Allele 2.

$P$ exp: expected frequency of homozygous Allele 1.

$Q$ exp: expected frequency of homozygous Allele 2 .

$2 P Q$ exp: expected frequency of heterozygotes.

${ }^{*}$ Genotypic and allelic frequencies are not in Hardy-Weinberg equilibrium.

If $\chi^{2}$ calculated $<\chi^{2}$ tabulated, do not reject null hypothesis.

If $\chi^{2}$ calculated $>\chi^{2}$ tabulated, reject null hypothesis.

TABLE 2: Single marker association of SORL1 SNPs in elderly Filipinos using Haploview.

\begin{tabular}{lccc}
\hline \multirow{2}{*}{ SNP number } & \multicolumn{3}{c}{ Single marker association } \\
& Risk allele & $\chi^{2}$ & $P$ value \\
\hline 8 & $\mathrm{C}$ & 0.871 & 0.350 \\
9 & $\mathrm{G}$ & 1.01 & 0.315 \\
10 & $\mathrm{G}$ & 1.01 & 0.315 \\
13 & $\mathrm{G}$ & 3.49 & 0.062 \\
19 & $\mathrm{G}$ & 1.015 & 0.314 \\
23 & $\mathrm{~A}$ & 1.687 & 0.192 \\
\hline
\end{tabular}

$=0.041)$ and SNP $23\left(P\right.$ value $\left._{\mathrm{AA}}=0.016\right)$ were associated with CI. SNP $8\left(P\right.$ value $\left._{\mathrm{TC}}=0.028\right)$, SNP $9\left(P\right.$ value $\left._{\mathrm{GA}}=0.034\right)$, SNP $10\left(P\right.$ value $\left._{\mathrm{GA}}=0.034\right)$, and SNP $23\left(P\right.$ value $_{\mathrm{AA}}=0.026$, $P$ value $\left._{\mathrm{TA}}=0.007\right)$ showed association with MCI. The six (6) SORL1 SNPs did not show association with AD.

Association of SORL1 with sex and age was also evaluated (Table 4). The 6 SORL1 SNPs were not associated with the $\mathrm{CI}, \mathrm{AD}$, and MCI cases in the male group. In the female group, SNPs $13(P$ value $=0.045)$ and $23\left(P\right.$ value $_{\mathrm{AA}}=0.017$; $P$ value $\left._{\mathrm{TA}}=0.017\right)$ were associated with CI, SNP 23 was associated with MCI $\left(P\right.$ value $=0.033 ; P$ value $_{\mathrm{AA}}=0.011$; $P$ value $\left._{\mathrm{TA}}=0.013\right)$, and no SORL1 SNP was associated with AD.

Based on the mean age, subjects were divided into two: the $\leq 70 \mathrm{y} / \mathrm{o}$ and the $>70 \mathrm{y} / \mathrm{o}$ groups. In the $\leq 70 \mathrm{y} / \mathrm{o}$ group, SNPs 19 and 23 were associated with CI (SNP 19: $P$ value $_{\mathrm{GG}}$ $=0.021 ; P$ value $_{\mathrm{TG}}=0.029$ and SNP 23: $P$ value $_{\mathrm{AA}}=0.025$; $P$ value $\left._{\mathrm{TA}}=0.021\right)$ and MCI (SNP 19: $P$ value $_{\mathrm{GG}}=0.038$ and SNP 23: $P$ value $_{\mathrm{AA}}=0.021 ; P$ value $\left._{\mathrm{TA}}=0.018\right)$, and no association was observed for the $\mathrm{AD}$ cases. For the $>70 \mathrm{y} / \mathrm{o}$ group, there was no association detected between the 6 SNPs and the CI, MCI, and AD cases.

SORL1 showed no association with the $A P O E-\varepsilon 4$ carriers. For the APOE- 44 noncarriers, SORL1 was significantly associated with CI (SNP 23: $P$ value $=0.008 ; P$ value $_{\mathrm{AA}}=0.020$; $P$ value $\left._{\mathrm{TA}}=0.002\right)$. SNP $8\left(P\right.$ value $=0.030 ; P$ value $_{\mathrm{GA}}=$ $0.019)$, SNPs 9 and $10\left(P\right.$ value $=0.050 ; P$ value $\left._{\mathrm{GA}}=0.025\right)$, SNP $19\left(P\right.$ value $_{\mathrm{GG}}=0.046 ; P$ value $\left._{\mathrm{TG}}=0.031\right)$, and SNP 23 $\left(P\right.$ value $_{\mathrm{AA}}=0.017 ; P$ value $\left._{\mathrm{TA}}=0.002\right)$ were associated with MCI. All 6 SORL1 SNPs were not significantly associated with $\mathrm{AD}$ (Table 3).

\section{Discussion}

When two or more alleles are in strong LD, it means that these alleles are inherited together. There are millions of polymorphisms in the human genome, many of which are in LD with each other; thus, it is not necessary to test all polymorphisms [12]. In this study, the block of SNPs 8, 9, and 10 was in strong equilibrium. However, none of the haplotypes were associated with $\mathrm{CI}, \mathrm{MCI}$, and $\mathrm{AD}$. This result did not replicate the findings from the Caribbean-Hispanic, Israeli-Arab, and North European datasets [2], but a similar result was reported for the Han Chinese population [13].

Our data showed SORL1 was associated with CI. But when restricted to $\mathrm{AD}$ and MCI, SORL1 was associated with MCI but not with AD. SORL1 has been reported to affect $\mathrm{AD}$ in different population but replication studies have given inconsistent results $[3-7,14]$. The meta-analysis study by Reitz and colleagues suggested that negative findings were likely related to underpowered studies with small sample 


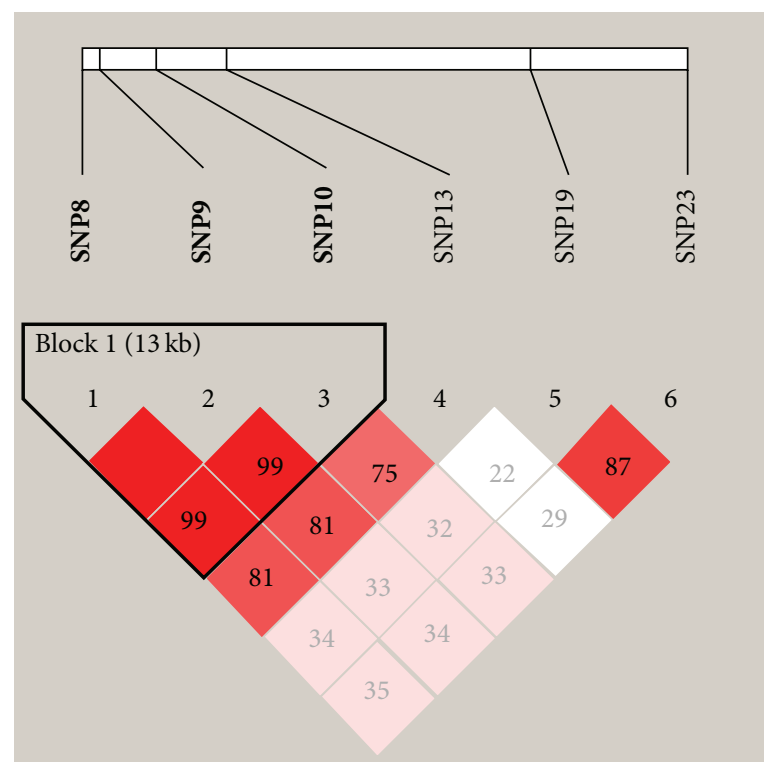

FIGURE 2: Linkage disequilibrium between the SORL1 SNPs. The standard Linkage disequilibrium color scheme was (D'/LOD) with white to red colors representing the increasing strength of Linkage disequilibrium. Block 1 (SNPs 8, 9, and 10) is in strong Linkage disequilibrium, resulting in haplotypes, T-A-A, and C-G-G with frequencies 0.673 and 0.323 .

TABLE 3: Association analysis of the SORL1 SNPs in Filipinos with CI, MCI, and AD.

\begin{tabular}{|c|c|c|c|c|c|c|}
\hline \multirow{2}{*}{ SORL1 SNPs } & \multicolumn{2}{|r|}{$\mathrm{CI}$} & \multicolumn{2}{|r|}{ MCI } & \multicolumn{2}{|r|}{$\mathrm{AD}$} \\
\hline & $P$ value & OR (95\% CI) & $P$ value & OR $(95 \% \mathrm{CI})$ & $P$ value & OR $(95 \% \mathrm{CI})$ \\
\hline SNP 8 & 0.225 & & 0.076 & & 0.829 & \\
\hline \multicolumn{7}{|l|}{ TT } \\
\hline TC & 0.091 & $1.389(0.949-2.033)$ & 0.028 & $1.710(1.060-2.760)$ & 0.586 & $1.146(0.701-1.875)$ \\
\hline $\mathrm{CC}$ & 0.857 & $1.056(0.586-1.904)$ & 0.858 & $1.073(0.498-2.320)$ & 0.914 & $0.959(0.446-2.060)$ \\
\hline SNP 9 & 0.256 & & 0.101 & & 0.829 & \\
\hline \multicolumn{7}{|l|}{ AA } \\
\hline GA & 0.102 & $1.375(0.939-2.014)$ & 0.034 & $1.680(1.040-2.715)$ & 0.586 & $1.146(0.701-1.875)$ \\
\hline GG & 0.754 & $1.098(0.612-1.970)$ & 0.682 & $1.171(0.552-2.483)$ & 0.914 & $0.959(0.446-2.060)$ \\
\hline SNP 10 & 0.256 & & 0.101 & & 0.829 & \\
\hline \multicolumn{7}{|l|}{$\mathrm{AA}$} \\
\hline GA & 0.102 & $1.375(0.939-2.014)$ & 0.034 & $1.680(1.040-2.715)$ & 0.586 & $1.146(0.701-1.875)$ \\
\hline GG & 0.754 & $1.098(0.612-1.970)$ & 0.682 & $1.171(0.552-2.483)$ & 0.914 & $0.959(0.446-2.060)$ \\
\hline SNP 13 & 0.041 & & 0.316 & & 0.085 & \\
\hline \multicolumn{7}{|l|}{ AA } \\
\hline GA & 0.667 & $0.348(0.071-1.709)$ & 0.350 & $0.402(0.060-2.795)$ & 0.173 & $0.256(0.036-1.819)$ \\
\hline GG & 0.193 & $0.718(0.159-3.249)$ & 0.671 & $0.676(0.111-0.4112)$ & 0.629 & $0.641(0.446-3.900)$ \\
\hline SNP 19 & 0.289 & & 0.177 & & 0.596 & \\
\hline \multicolumn{7}{|l|}{$\mathrm{TT}$} \\
\hline TG & 0.120 & $1.529(0.895-2.611)$ & 0.075 & $1.921(0.920-4.014)$ & 0.317 & $1.421(0.715-2.825)$ \\
\hline GG & 0.187 & $1.443(0.837-2.488)$ & 0.082 & $1.965(0.934-4.134)$ & 0.537 & $1.249(0.617-2.528)$ \\
\hline SNP 23 & 0.055 & & 0.025 & & 0.309 & \\
\hline \multicolumn{7}{|l|}{ TT } \\
\hline TA & 0.089 & $1.861(1.123-3.085)$ & 0.007 & $2.708(1.319-5.559)$ & 0.135 & $1.637(0.858-3.123)$ \\
\hline AA & 0.016 & $1.581(0.931-2.682)$ & 0.026 & $2.329(1.105-4.908)$ & 0.425 & $1.321(0.667-2.616)$ \\
\hline
\end{tabular}


TABLE 4: SORL1 SNPs analyses that showed significant association in Filipinos with CI and MCI according to sex and age groups and APOE- 44 carriage.

\begin{tabular}{|c|c|c|c|c|c|c|}
\hline \multirow{2}{*}{ SORL1 SNPs } & \multicolumn{2}{|r|}{ CI } & \multicolumn{2}{|r|}{ MCI } & \multicolumn{2}{|r|}{$\mathrm{AD}$} \\
\hline & $P$ value & OR $(95 \% \mathrm{CI})$ & $P$ value & OR $(95 \% \mathrm{CI})$ & $P$ value & OR (95\% CI) \\
\hline \multicolumn{7}{|l|}{ Females } \\
\hline SNP 13 & 0.045 & & 0.147 & & 0.169 & \\
\hline \multicolumn{7}{|l|}{$\mathrm{AA}$} \\
\hline GA & 0.464 & $0.344(0.020-5.974)$ & 0.214 & $0.156(0.008-2.919)$ & & \\
\hline GG & 0.915 & $0.859(0.530-13.865)$ & 0.509 & $0.391(0.024-6.351)$ & & \\
\hline SNP 23 & 0.052 & & 0.033 & & 0.359 & \\
\hline \multicolumn{7}{|l|}{$\mathrm{TT}$} \\
\hline TA & 0.017 & $2.156(1.144-4.063)$ & 0.013 & $3.566(1.300-9.778)$ & 0.154 & $1.783(0.804-3.951)$ \\
\hline $\mathrm{AA}$ & 0.037 & $2.016(1.043-3.895)$ & 0.011 & $3.762(1.347-10.508)$ & 0.261 & $1.612(0.701-3.708)$ \\
\hline \multicolumn{7}{|l|}{$\leq 70$ years old } \\
\hline SNP 19 & 0.062 & & 0.113 & & 0.288 & \\
\hline \multicolumn{7}{|l|}{ TT } \\
\hline TG & 0.029 & $2.742(1.107-6.792)$ & 0.059 & $2.985(0.960-9.281)$ & 0.125 & $5.118(0.636-41.202)$ \\
\hline GG & 0.021 & $2.920(1.172-7.277)$ & 0.038 & $3.328(1.067-10.375)$ & 0.122 & $5.230(0.644-42.463)$ \\
\hline SNP 23 & 0.555 & & 0.052 & & 0.534 & \\
\hline \multicolumn{7}{|l|}{ TT } \\
\hline TA & 0.021 & $2.576(1.127-5.887)$ & 0.018 & $3.864(1.258-11.869)$ & 0.434 & $1.717(0.443-6.653)$ \\
\hline AA & 0.025 & $2.670(1.157-6.164)$ & 0.021 & $3.810(1.225-11.850)$ & 0.265 & $2.149(0.560-8.250)$ \\
\hline \multicolumn{7}{|c|}{ APOE-E4 noncarriers } \\
\hline SNP 8 & 0.125 & & 0.030 & & 0.778 & \\
\hline \multicolumn{7}{|l|}{$\mathrm{TT}$} \\
\hline $\mathrm{TC}$ & 0.088 & $1.446(0.946-2.211)$ & 0.019 & $1.865(1.106-3.146)$ & 0.789 & $1.081(0.611-1.913)$ \\
\hline $\mathrm{CC}$ & 0.556 & $0.815(0.412-1.612)$ & 0.617 & $0.792(0.318-1.973)$ & 0.575 & $0.771(0.310-1.917)$ \\
\hline SNP 9 & 0.167 & & 0.050 & & 0.778 & \\
\hline \multicolumn{7}{|l|}{ AA } \\
\hline GA & 0.100 & $1.429(0.934-2.186)$ & 0.025 & $1.825(1.080-3.084)$ & 0.789 & $1.081(0.611-1.913)$ \\
\hline GG & 0.674 & $0.866(0.422-1.695)$ & 0.824 & $0.905(0.378-2.170)$ & 0.575 & $0.771(0.310-1.917)$ \\
\hline SNP 10 & 0.167 & & 0.050 & & 0.778 & \\
\hline \multicolumn{7}{|l|}{ AA } \\
\hline GA & 0.100 & $1.429(0.934-2.186)$ & 0.025 & $1.825(1.080-3.084)$ & 0.789 & $1.081(0.611-1.913)$ \\
\hline GG & 0.674 & $0.866(0.422-1.695)$ & 0.824 & $0.905(0.378-2.170)$ & 0.575 & $0.771(0.310-1.917)$ \\
\hline SNP 19 & 0.151 & & 0.091 & & 0.554 & \\
\hline \multicolumn{7}{|l|}{ TT } \\
\hline TG & 0.062 & $1.818(0.970-3.409)$ & 0.031 & $2.653(1.095-6.426)$ & 0.393 & $1.439(0.624-3.322)$ \\
\hline GG & 0.075 & $1.773(0.945-3.327)$ & 0.046 & $2.468(1.015-6.000)$ & 0.278 & $1.583(0.691-3.629)$ \\
\hline SNP 23 & 0.008 & & 0.007 & & 0.162 & \\
\hline \multicolumn{7}{|l|}{ TT } \\
\hline TA & 0.002 & $2.563(1.410-4.657)$ & 0.002 & $4.023(1.694-9.554)$ & 0.058 & $2.190(0.973-4.933)$ \\
\hline AA & 0.020 & $2.073(1.121-3.834)$ & 0.017 & $2.962(1.216-7.215)$ & 0.114 & $1.954(0.851-4.490)$ \\
\hline
\end{tabular}

sizes, allelic heterogeneity, or both. Because AD is a complex disease, it is also likely that interaction between two or more genes contributes to disease's phenotype.

The relationship between SORL1 and MCI remains unclear but may suggest that MCI can be modulated by SORL1 like how it is modulated by APOE. Whitehair et al. reported the influence of $A P O E-\varepsilon 4$ genotype on rates of cognitive decline in MCI. They found out that APOE$\varepsilon 4$ carriers had significantly more rapid decline in cognitive and functional performance [15]. On the other hand, SORL1 expression in individuals with MCI was heterogeneous, such that some MCI cases had SORL1 expression similar to healthy controls while it was reduced in others to levels similar to those seen in $\mathrm{AD}[10,16]$. These reports indicate that SORL1 and $A P O E$ have similar effect on the cognition of individuals with MCI.

SORL1 (SNP 23) was significantly associated with the female sex in this study. A previous report showed a similar 
result wherein SORL1 (SNP 4) was also associated with the female sex [6]. For individuals over the age of 80 , women are at slightly higher risk of $\mathrm{AD}$, while men may be at higher risk of vascular dementia [17]. Prevalence of MCI in males was higher than that in females; however, the transition in women from normal cognition to dementia is more abrupt in women [18]. The importance of estrogen receptor-mediated neuroprotection in females was cited as a plausible factor in cognition [19]. These reports suggest the possible sex-specific interplay of risk factors, disease course, and survival in this disease.

As we grow older, our cognitive abilities gradually decline. For $\mathrm{AD}$, age is a major risk factor [2]. Around $50 \%$ of all people more than 85 years old suffer from AD [20]. Interestingly, no association was observed in the $>70 \mathrm{y} / \mathrm{o}$ group with $\mathrm{CI}, \mathrm{MCI}$, and $\mathrm{AD}$. Interestingly, the $\leq 70 \mathrm{y} / \mathrm{o}$ group was associated with SORL1 in the CI and MCI cases. We hypothesized that the sample size, subject heterogeneity, and age range in our groupings may be the reasons why we were not able to replicate the positive results of Rogaeva et al.

The association of SORL 1 with CI, female sex, and $\leq 70 \mathrm{y} / \mathrm{o}$ group elucidated in this study may indicate the early effects of this gene in the development of CI leading to dementia.

It has been suggested that SORL1 activity is influenced by APOE [20]. Alterations in the three-dimensional structure and binding properties of APOE in the APOE- 44 isoform may result in changes in the interaction between SORL1 and APOE that could affect the capacity of SORL1 to bind to APP. Thus, the APOE isoform may have a modifying effect on the association of SORL1 and APOE; specifically, effects of distinct SORL1 SNPs may be weakened by the APOE- $\varepsilon 4$ allele. Several studies showed association of SORL1 SNPs with AD in $A P O E-\varepsilon 4$ noncarriers $[7,21]$.

In this study, significant association of the SORL1 SNPs was detected with $\mathrm{MCI}$ and $\mathrm{CI}$ in APOE- $\varepsilon 4$ noncarriers but not with $\mathrm{AD}$. To determine possible interaction of $S O R L 1$ and $A P O E$, we also tested the association of $A P O E-\varepsilon 4$ allele with $\mathrm{CI}, \mathrm{MCI}$, and $\mathrm{AD}$. The result showed that $A P O E-\varepsilon 4$ allele was associated with $\mathrm{AD}(P$ value $=0.017) . A P O E-\varepsilon 4$ allele was not associated with CI $(P$ value $=0.140)$ and MCI $(P$ value $=0.870)$. Based on this result, it could be possible that the presence of $A P O E-\varepsilon 4$ allele may have masked the effect of the SORL1 in AD. These data support the role of SORL1 in $\mathrm{AD}$ pathogenesis, contributing to an increased risk to $\mathrm{CI}$ even when the APOE- $\varepsilon 4$ allele is not present.

Because SORL1 plays a crucial role in APP processing, it is a reliable gene that could help fill up missing links in the complex genetics of $\mathrm{AD}$ and other CIs. This study provides baseline information on the possible contribution of SORL1 to increased risk of CI in Filipinos. Although no association was observed between the SORL1 and AD, our findings provide evidence that $S O R L 1$ may signal a predisposition to cognitive impairment in Filipinos.

\section{Conflict of Interests}

The authors declare that there is no conflict of interests regarding the publication of this paper.

\section{Acknowledgments}

This study was funded by a grant from the Research and Biotechnology, the St. Luke's Medical Center, Quezon City, Philippines. The authors are grateful for the assistance given by the Memory Center of the St. Luke's Medical Center, the St. Luke's College of Medicine, and the Senior Citizen Community of Marikina City, Philippines.

\section{References}

[1] J. H. Lee, R. Cheng, L. S. Honig, J.-P. G. Vonsattel, L. Clark, and R. Mayeux, "Association between genetic variants in SORL1 and autopsy-confirmed Alzheimer disease," Neurology, vol. 70, no. 11, pp. 887-889, 2008.

[2] E. Rogaeva, Y. Meng, J. H. Lee et al., "The neuronal sortilinrelated receptor SORL1 is genetically associated with Alzheimer disease," Nature Genetics, vol. 39, no. 2, pp. 168-177, 2007.

[3] N. Shibata, T. Ohnuma, H. Baba, S. Higashi, K. Nishioka, and H. Arai, "Genetic association between SORL1 polymorphisms and Alzheimer's disease in a Japanese population," Dementia and Geriatric Cognitive Disorders, vol. 26, no. 2, pp. 161-164, 2008.

[4] C. Reitz, R. Cheng, E. Rogaeva et al., "Meta-analysis of the association between variants in SORL1 and Alzheimer disease," Archives of Neurology, vol. 68, no. 1, pp. 99-106, 2011.

[5] K. Bettens, N. Brouwers, S. Engelborghs, P. P. De Deyn, C. Van Broechoven, and K. Sleegers, "SORL1 is genetically associated with increased risk for late-onset Alzheimer disease in the Belgian population," Human Mutation, vol. 29, no. 5, pp. 769770, 2008.

[6] E. Cellini, A. Tedde, S. Bagnoli et al., "Implication of sex and SORL1 variants in Italian patients with Alzheimer disease," Archives of Neurology, vol. 66, no. 10, pp. 1260-1266, 2009.

[7] R. Kimura, M. Yamamoto, T. Morihara et al., "SORL1 is genetically associated with Alzheimer's disease in Japanese population," Neuroscience Letters, vol. 461, no. 2, pp. 177-180, 2009.

[8] R. Mayeux and P. St George-Hyslop, "Alzheimer's disease 2007: mind the traffic," The Lancet Neurology, vol. 7, no. 1, pp. 2-3, 2008.

[9] H. Zheng and E. H. Koo, "The amyloid precursor protein: beyond amyloid," Molecular Neurodegeneration, vol. 1, no. 1, article 5, 2006.

[10] K. L. Sager, J. Wuu, S. E. Leurgans et al., "Neuronal LR11/SorLA expression is reduced in mild cognitive impairment," Annals of Neurology, vol. 62, no. 6, pp. 640-647, 2007.

[11] C. Reitz, C. Brayne, and R. Mayeux, "Epidemiology of Alzheimer disease," Nature Reviews Neurology, vol. 7, no. 3, pp. 137152, 2011.

[12] C.-H. Lin, Linkage disequilibrium measures [Master of Science in Statistics], UCLA, 2005.

[13] E. K. Tan, J. Lee, C. P. Chen, Y. Y. Teo, Y. Zhao, and W. L. Lee, "SORL1 haplotypes modulate risk of Alzheimer's disease in Chinese," Neurobiology of Aging, vol. 30, no. 7, pp. 1048-1051, 2009.

[14] R. L. Minster, S. T. DeKosky, and M. I. Kamboh, "No association of SORL1 SNPs with Alzheimer's disease," Neuroscience Letters, vol. 440, no. 2, pp. 190-192, 2008.

[15] D. C. Whitehair, A. Sherzai, J. Emond et al., "Influence of apolipoprotein e $\varepsilon 4$ on rates of cognitive and functional decline in 
mild cognitive impairment," Alzheimer's and Dementia, vol. 6, no. 5, pp. 412-419, 2010.

[16] K. E. Grear, I.-F. Ling, J. F. Simpson et al., "Expression of SORL1 and a novel SORL1 splice variant in normal and Alzheimers disease brain," Molecular Neurodegeneration, vol. 4, article 46, 2009.

[17] Alzheimer's Association, "Alzheimer's disease: facts and figures," Alzheimer's and Dementia, vol. 6, pp. 1-74, 2010.

[18] R. C. Petersen, R. O. Roberts, D. S. Knopman et al., "Prevalence of mild cognitive impairment is higher in men: the Mayo Clinic Study of Aging," Neurology, vol. 75, no. 10, pp. 889-897, 2010.

[19] A. Peri and M. Serio, "Estrogen receptor-mediated neuroprotection: the role of the Alzheimer's disease-related gene seladin-1," Neuropsychiatric Disease and Treatment, vol. 4, no. 4, pp. 817824, 2008.

[20] R. Perneczky, P. Alexopoulos, T. Eisele, H. Forstl, and A. Kurz, "Does the apolipoprotein E genotype influence amyloid precursor protein sorting by sortilin-related receptor: implications for Alzheimer's disease?" Medical Hypotheses and Research, vol. 6, pp. 19-24, 2010.

[21] J. H. Lee, N. Shibata, R. Cheng, and R. Mayeux, "Possible association between SORL1 and Alzheimer's disease?" Dementia and Geriatric Cognitive Disorders, vol. 26, p. 48, 2008. 

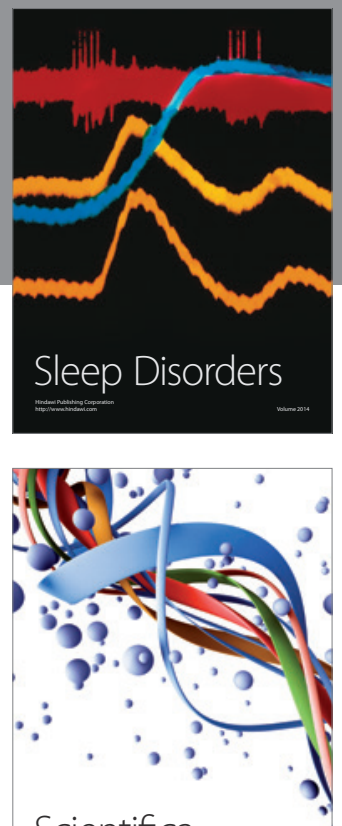

Scientifica
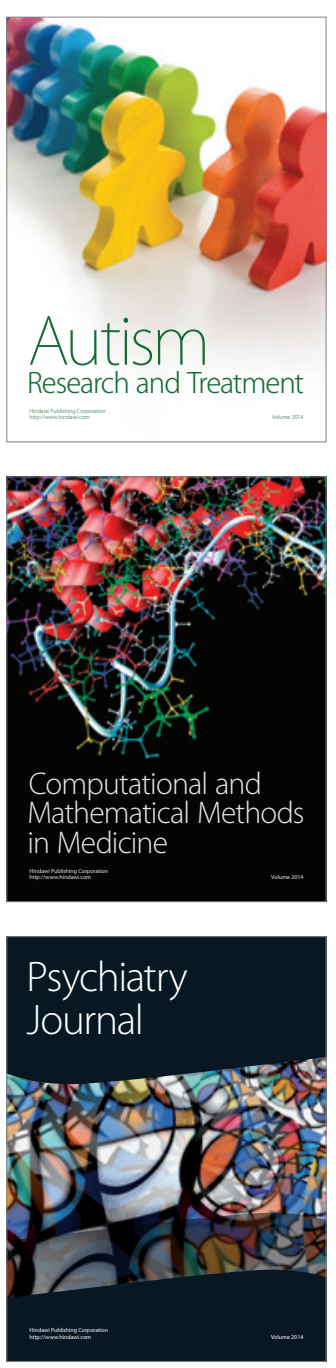
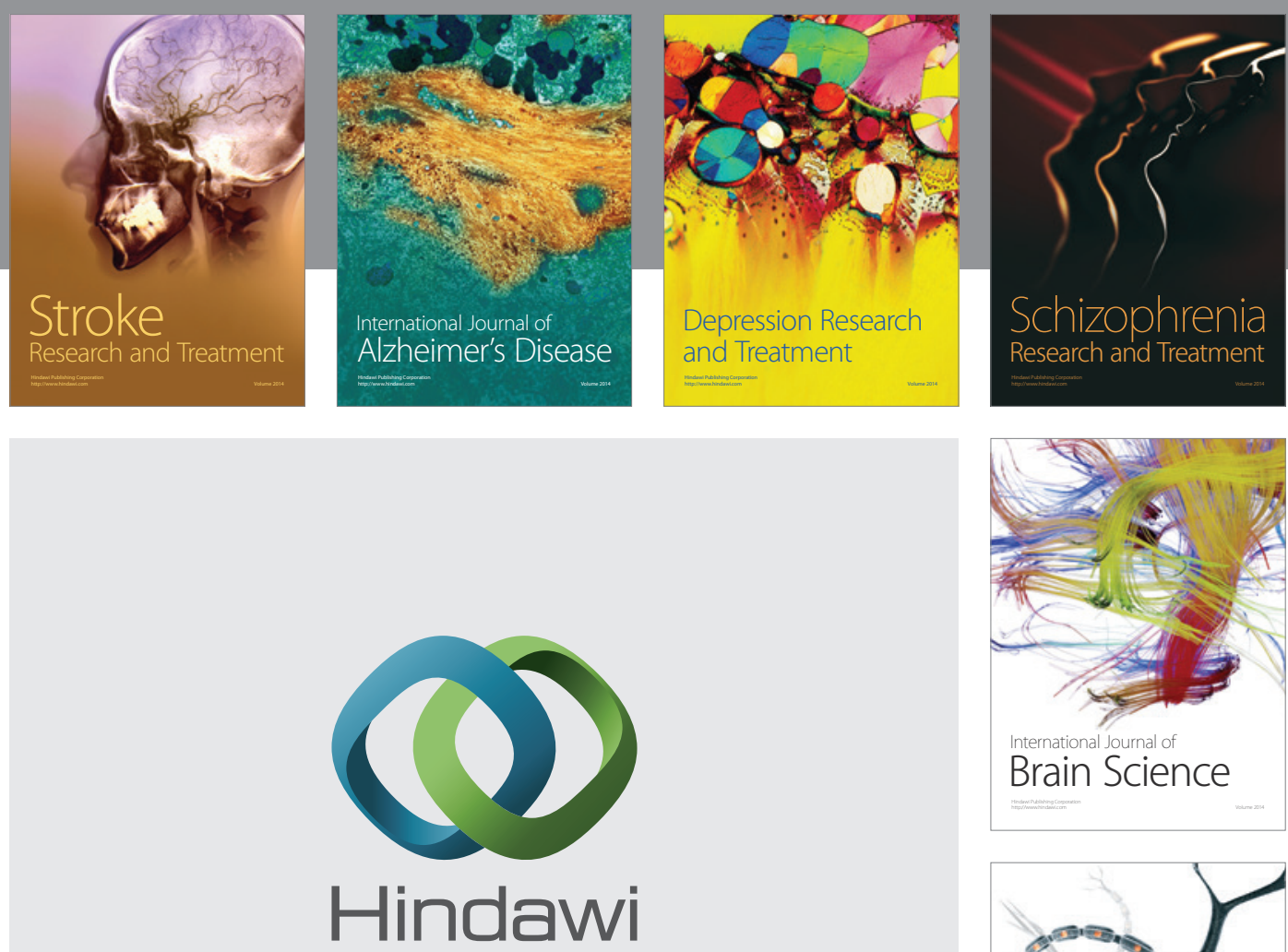

Submit your manuscripts at

http://www.hindawi.com
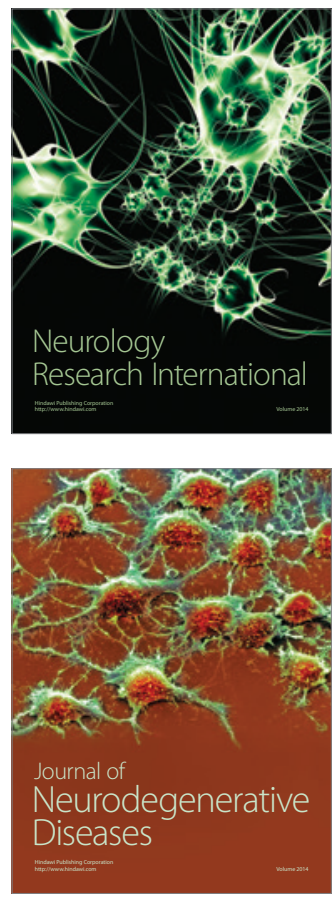

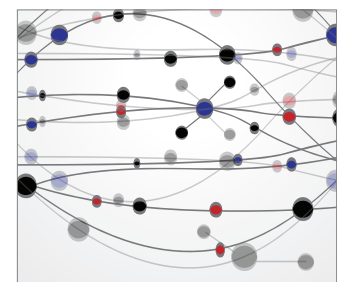

The Scientific World Journal
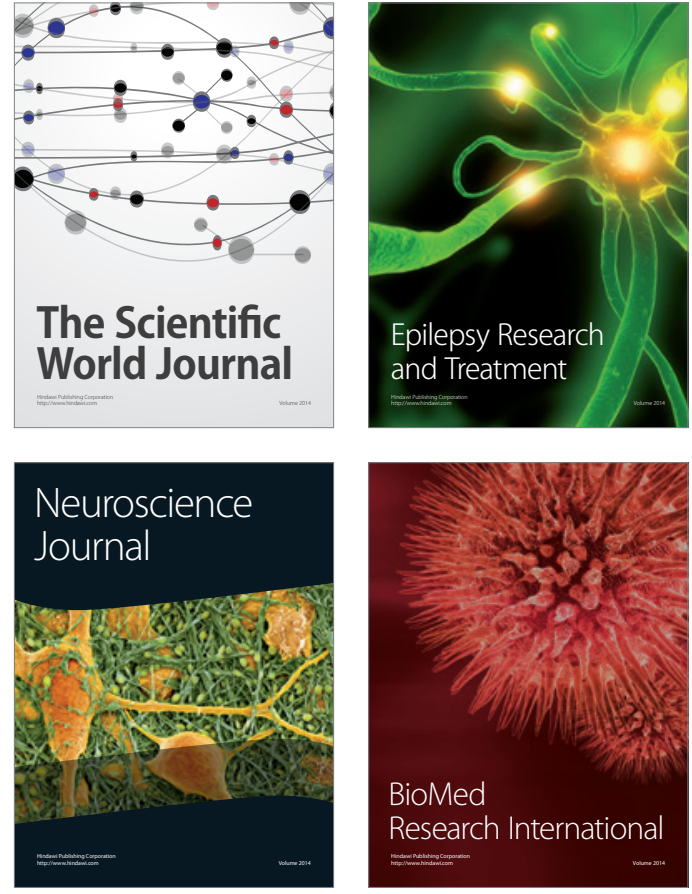

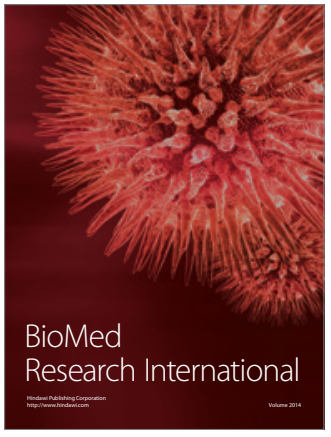

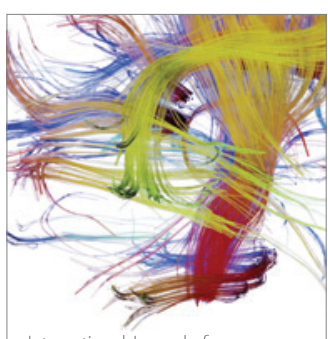

Brain Science

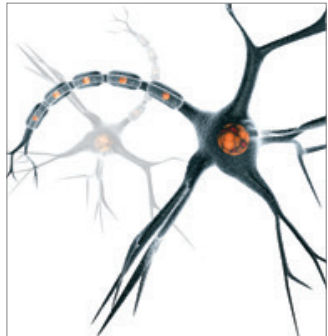

Neural Plasticity
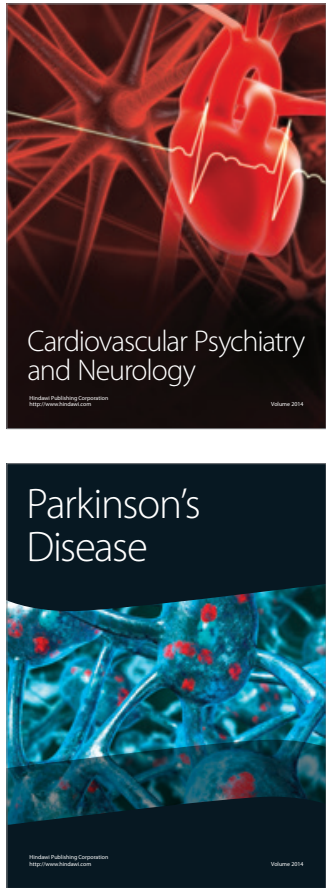